\title{
The prevalence of undiagnosed chronic obstructive pulmonary disease in a primary care population with respiratory tract infections - a case finding study
}

Hanna Sandelowsky ${ }^{1,2^{*}}$, Björn Ställberg ${ }^{3}$, Anna Nager ${ }^{1}$ and Jan Hasselström ${ }^{1}$

\begin{abstract}
Background: Chronic obstructive pulmonary disease (COPD) is an underdiagnosed cause of morbidity and mortality worldwide. Prevalence of COPD has been shown to be highly associated with positive smoking history and increasing age. Spirometry is the method used for diagnosing COPD. However, identifying patients at risk of COPD to undergo spirometry tests has been challenging. Therefore, there is a need for new cost-effective and feasible diagnostic screening procedures for use in primary care centers. Our aim was to describe the prevalence and severity of undiagnosed COPD in a group of patients with respiratory infections attending urgent primary care, and to identify those variables in patients' history that could be used to detect the disease.

Methods: Patients of 40-75 years $(n=138)$ attending urgent primary care center with acute respiratory tract infection, positive smoking history and no previously known pulmonary disease underwent pre- and post bronchodilator spirometry testing four to five weeks after the acute infection. Prevalence and severity of COPD were estimated following the Global Initiative for COPD (GOLD) criteria. Variables such as sex, age, current smoking status, smoking intensity (pack years) and type of infection diagnosis were assessed for possible associations with COPD.

Results: The prevalence of previously undiagnosed COPD in our study group was 27\%, of which $45 \%$ were in stage 1 (FEV1 $\geq 80 \%$ of predicted), $53 \%$ in stage 2 ( $50 \leq \mathrm{FEV} 1<80 \%$ of predicted), $3 \%$ in stage 3 ( $30 \leq \mathrm{FEV} 1<$ $50 \%$ of predicted) and $0 \%$ in stage 4 (FEV1 $<30 \%$ of predicted). We found a significant association between COPD and age $\geq 55(\mathrm{OR}=10.9[95 \% \mathrm{Cl}$ 3.8-30.1]) and between COPD and smoking intensity (pack years $>20)(\mathrm{OR}=3.2$ [95\% Cl 1.2-8.5]). Sex, current smoking status and type of infection diagnosis were not shown to be significantly associated with COPD.
\end{abstract}

Conclusion: A middle-aged or older patient with any type of common respiratory tract infection, positive smoking history and no previously known pulmonary disease has an increased likelihood of having underlying COPD. These patients should be offered spirometry testing for diagnosis of COPD.

\section{Background}

Chronic obstructive pulmonary disease (COPD) is an underdiagnosed cause of morbidity and mortality worldwide [1], with an estimated prevalence of $3-12 \%$ [2-4]. COPD causes suffering and adds substantial burden to national healthcare budgets [5]. An early diagnosis may

\footnotetext{
* Correspondence: hanna.sandelowsky@sll.se

${ }^{1}$ Center for Family and Community Medicine (CeFAM), Department of Neurobiology, Care Sciences and Society, Karolinska Institutet, Alfred Nobels Allé 12, S-14183 Huddinge, Sweden

Full list of author information is available at the end of the article
}

motivate smoking cessation which is the only measure known to radically improve future prospects for the patient [6].

The prevalence of COPD increases considerably with age and intensity of smoking, and can vary from $25 \%$ in a general smoking population to approximately $50 \%$ in the elderly smoking population [4,7-9]. Most subjects with undiagnosed COPD have a mild form of the disease. Underdiagnosis most frequently involves patients at early stages of COPD; approximately $95 \%$ of those in

\section{Biomed Central}


stage 1 (mild COPD) and $80 \%$ of those in stage 2 (moderate COPD) remain undiagnosed [10].

Spirometry is the basis for diagnosis [11]. However, primary care providers, who often meet patients with respiratory symptoms, do not always have access, time or adequate training to use this method [12]. Alternatively, symptom-based questionnaires are available to enhance COPD screening in primary care $[13,14]$, but are often considered time-consuming in a typical urgent care setting. To identify patients at risk of COPD and test them using spirometry has been challenging [15]. For all the reasons mentioned above, easy diagnostic screening procedures that are feasible in primary care settings are much needed $[16,17]$

Due to histopathological and immunological changes in their respiratory tract, smokers are more susceptible to prolonged complicated infections [18]. There is increasing evidence implicating viral infections of the respiratory tract to exacerbation of COPD. Thus, symptoms of both upper and lower respiratory tract infection may in fact be signs of underlying COPD [19-22]. There is a need for more studies into new methods for early detection of COPD. At the same time, different ways of "case finding" have been discussed [17,23]. Symptoms of an underlying chronic lung disease may become obvious when a patient develops an acute respiratory tract infection, since patients often become habituated to their symptoms and do not report them to their physicians during consultations [24]. In light of this, spirometry testing on smokers with respiratory tract infections could constitute a targeted approach to screening for underlying COPD and was assessed here for the first time.

We conducted a cross-sectional study whose aim was to measure the prevalence and severity of undiagnosed COPD among urgent care patients with respiratory tract infections who had a positive smoking history but no prior pulmonary disease diagnosis. An additional aim for this study was to explore whether simple variables in a patient's history coupled with the respiratory infection could be indicative of COPD.

\section{Methods}

Patients were invited to participate in the study between January-March 2005 when they sought medical attention due to respiratory tract infections. All patients had visited either a primary health care center or an urgent primary care unit in a suburban area of Stockholm, Sweden. Patients, aged 40-75 years, who were eligible and agreed to participate were either current smokers (or smokingfree for no more than 6 months), or ex-smokers who had come to an urgent primary care unit because they had experienced symptoms of respiratory infection and had received subsequent diagnosis (Table 1). Patients with poor knowledge of Swedish, severe cardiac, psychiatric or multi-organ disease, prior history of lung disease (except for asthma) and those on medication with beta-blockers were excluded. A consecutive sample of patients with an ICD-10 diagnosis for respiratory tract infections was then extracted from the medical records. The diagnoses were subsequently validated by reviewing the medical records. Patients who fit the inclusion criteria were contacted by telephone. Telephone conversations were complemented with formal written invitations sent by post together with information about the study. According to the enrolment plan (Figure 1), which had been approved by the Regional Board of Ethics in Stockholm, Sweden, informed verbal consent was obtained both by telephone and prior to spirometry testing. Spirometry was performed four to five weeks after patients were diagnosed with acute respiratory infection, when respiratory function was no longer considered to be affected by the infection [25]. Participants were also asked to provide information about their smoking intensity ("pack years", table 2). An "office desk" spirometer (Vitalograph Alpha spirometry) that was calibrated daily according to manufacturer's instructions was used. A reference equation by the European Community for Coal and Steel (ECCS) was chosen for reference values [26]. All patients showing airway limitations $(\mathrm{FEV} 1 / \mathrm{FVC}<0.7)$ on the baseline test were given a beta- 2 agonist - 8 micrograms of formoterol via inhaler $\left(\right.$ Oxis $^{\circledR}$ Turbuhaler $^{\circledR}$ ). Post-bronchodilator spirometry was performed after 15 minutes. The COPD diagnosis

Table 1 Infection diagnoses according to ICD-10

\begin{tabular}{lll}
$\begin{array}{l}\text { Upper respiratory tract } \\
\text { infection }\end{array}$ & J00-J06 & $\begin{array}{l}\text { Acute infections in the upper respiratory system (nasopharyngitis, sinusitis, pharyngitis, tonsillitis, laryngitis, } \\
\text { obstructive laryngitis, acute upper respiratory infection NOS) }\end{array}$ \\
\hline $\begin{array}{l}\text { Lower respiratory tract } \\
\text { infection }\end{array}$ & J11-J18 & Pneumonia \\
\hline & J20-J22 & Other acute lower respiratory infections (bronchitis, bronchiolitis, acute lower respiratory infection NOS) \\
\hline R05 & Cough* \\
\hline $\begin{array}{l}\text { Viral infection or } \\
\text { influenza }\end{array}$ & B34 & Viral infection, unspecified \\
\hline & J10 & Influenza \\
\hline
\end{tabular}

\footnotetext{
* Patients having predominantly symptoms of lower respiratory tract infection but receiving diagnosis code R05.
} 


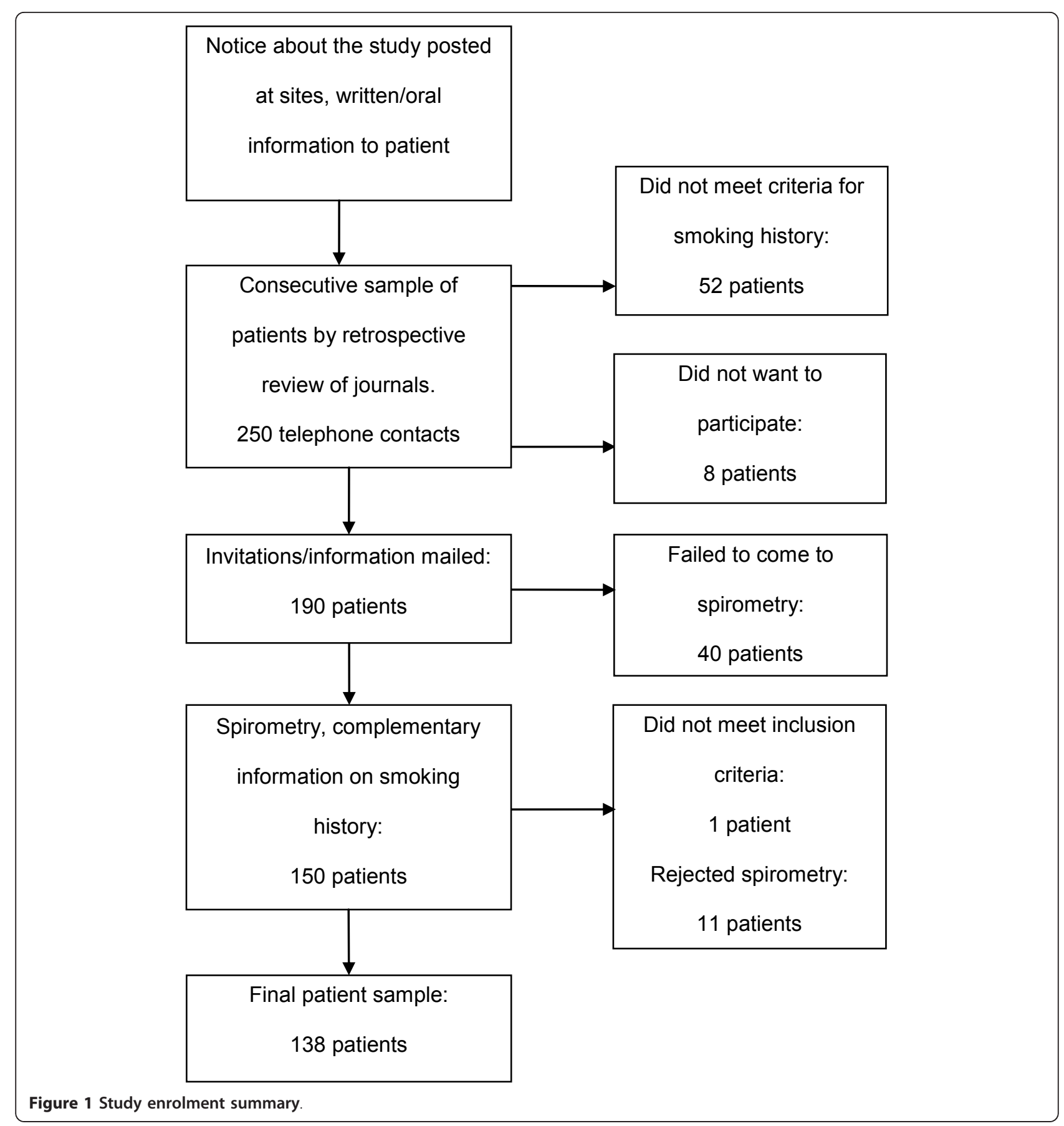

was made using the Global Initiative for Chronic Obstructive Lung Disease (GOLD) criteria [11]. Patients who needed further medical attention were referred to their family physicians.

\section{Statistical analysis}

The statistical analysis was performed using STATA, version 8 [27]. Summary statistics such as means, proportions and measures of dispersion were computed using standard parametric methods. Multiple logistic regression was used to analyze variables associated with a COPD diagnosis, which also provided odds ratios and their 95\% confidence intervals (CI). P-values $<0.05$ were indicative of statistical significance. We chose the receiver/response operating characteristic (ROC) curve to select the most optimal prediction method, or model, for variables associated with COPD, and to discard suboptimal ones independently from class distribution. 
Table 2 Description of 138 patients with respiratory tract infections seeking urgent primary care

\begin{tabular}{|c|c|c|c|c|}
\hline Variables & Total & COPD & & Non-COPD \\
\hline $\mathbf{N}(\%)$ & 138 & $38(27)$ & & $100(73)$ \\
\hline \multicolumn{5}{|l|}{ Age } \\
\hline Years, mean [95\%Cl] & $55[54-57]$ & $62[59-64]$ & & $53[51-55]$ \\
\hline Agegroup 40-54 years $n(\%)$ & 62 & $5(13)$ & & $57(57)$ \\
\hline Agegroup 55-70 years n (\%) & 76 & $33(87)$ & & $43(43)$ \\
\hline \multicolumn{5}{|l|}{ Smoking intensity } \\
\hline Pack years*, mean $[95 \% \mathrm{Cl}]$ & $24[22-26]$ & $32[27-36]$ & & $21[19-24]$ \\
\hline Pack years*, median [range] & 20 [5-75] & $31[5-75]$ & & $20[5-56]$ \\
\hline \multicolumn{5}{|l|}{ Smoking status } \\
\hline Current smokers, n (\%) & 73 & $25(65.8)$ & & $48(48.0)$ \\
\hline Former smokers, n (\%) & 65 & $13(34.2)$ & & $52(52.0)$ \\
\hline \multicolumn{5}{|l|}{ Diagnosis } \\
\hline Upper resp. infection, n (\%) & 57 & $15(39.5)$ & & $42(42.0)$ \\
\hline Lower resp. infection, n (\%) & 79 & $23(60.5)$ & & $56(56.0)$ \\
\hline Viral infection/influenza, n (\%) & 2 & $0(0)$ & & $2(2.0)$ \\
\hline \multicolumn{5}{|l|}{ Sex } \\
\hline Female, n (\%) & & $19(50)$ & & $58(58)$ \\
\hline Male & & $19(50)$ & & $42(42)$ \\
\hline \multicolumn{5}{|l|}{ Spirometry } \\
\hline FEV1\% of predicted, mean $[95 \% \mathrm{Cl}]$ & $95.7[92.6-98.8]$ & $77.5[71.2-84.0]$ & & $102.6[100.2-105.1]$ \\
\hline FEV1/FVC ratio, mean $[95 \% \mathrm{Cl}]$ & $0.73[0.71-0.75]$ & $0.60[0.57-0.63]$ & & $0.78[0.77-0.79]$ \\
\hline COPD severity** & & $\mathbf{N}$ & $\%$ & \\
\hline Stage 1 (mild, FEV1 $\geq 80 \%$ of predicted) & & 17 & $(44.7)$ & \\
\hline Stage 2 (moderate, $50 \% \leq \mathrm{FEV} 1<80 \%$ of predicted) & & 20 & $(52.6)$ & \\
\hline Stage 3 (severe, $30 \% \leq$ FEV1 < 50\% of predicted) & & 1 & $(2.6)$ & \\
\hline Stage 4 (very severe, FEV1 < 30\% of predicted) & & 0 & (0) & \\
\hline
\end{tabular}

Numbers in total and divided into groups with or without COPD.

${ }^{*}$ Number of pack years $=$ (number of cigarettes smoked per day $\times$ number of years smoked/20)

** According to Global Initiative for Chronic Obstructive Lung Disease (GOLD)

In order to show how well the model discriminated data we used standardized values describing the area under the ROC-curve (excellent $=0.90-1$, good $=0.80-.0 .90$, fair $=0.70-0.80$, poor $=0.60-0.70$ and fail $=0.50-0.60$ ). When plotting the curve, the closer the ROC curve is to the upper left corner, the higher the overall accuracy of the test [28]. Confidence intervals according to classification table were based on Wilson score method. Pvalues $<0.05$ were indicative of statistical significance.

In order to find a reasonable sample size, we chose the prevalence of $30 \%$, based on previous studies that resembled ours in design $[9,13]$. A random sample of 140 patients would have given a $95 \%$ confidence interval of $\pm 7 \%$ which was estimated to give a reasonable spread to meet the aims of the study.

\section{Ethical approval}

The project was approved by the Regional Board of Ethics in Stockholm, Sweden.

\section{Results}

Of the 138 eligible patients in urgent primary care, 38 were diagnosed with COPD, which corresponds to a prevalence of $27 \%$ (95\% CI $\pm 7 \%$ ). Prevalence among patients aged $55-75$ years was $43 \%$, whereas $8 \%$ was estimated for patients in the younger age group $(\mathrm{p}<0.001)$ (table 2). There were as many men as women diagnosed with COPD in the study group, though women were significantly younger than men (mean age 59 versus 64 years), $(p=0.023)$. Two thirds of all COPD cases were current smokers, the majority of them women $(\mathrm{p}=$ 0.087). Thirty-four per cent of current smokers and $20 \%$ of ex-smokers had COPD ( $\mathrm{p}=0.061)$. The average number of pack years among patients with COPD was 32. There was no significant difference in the distribution of upper respiratory tract infection (URTI) and lower respiratory tract infection (LRTI) between the COPD and non-COPD groups, while COPD was nearly equally distributed in URTI and LRTI groups. 
Specifically, 26\% of patients with URTI also had COPD, of which $47 \%$ were in stage 1 and $53 \%$ in stage 2 (none in stage 3 ). Similarly, $29 \%$ of patients with LRTI also had COPD, of which $44 \%$ were in stage 1, $52 \%$ in stage 2 and $4 \%$ in stage 3.

Figure 2 shows the spirometry results of all 138 patients, plotted as FEV1 in relation to FEV1/FVC. For COPD patients, the mean FEV1/FVC was 0.60 (min 0.43 , max 0.69 ) and the mean FEV1 was $77.5 \%$ (min $41 \%$, max $113 \%$ ) of the predicted value. Spirometry results, including severity grades of COPD and a summary of the data are shown in table 2. Lung function values were evenly distributed across all ages (Figure 3).

Multiple logistic regression analysis, using COPD as a response variable, revealed a statistically significant association between COPD and age $\geq 55$ years $(\mathrm{OR}=10.9$ [95\% CI 3.8-30.1], $\mathrm{p}<0.001$ ) and between COPD and pack years $\geq 20(\mathrm{OR}=3.2[95 \% \mathrm{CI} 1.2-8.5], \mathrm{p}=0.016)$, after adjustments for all explanatory variables were made (Table 3). Neither current smoking ( $\mathrm{OR}=2.5$ [95\% CI 0.9-6.6], $\mathrm{p}=0.071$ ) nor sex or location of infection diagnosis (URTI or LRTI) were significantly associated with COPD. Based on the observations above, a model for predicting COPD was created. The model included positive variables "age $\geq 55$ ", "pack years $\geq 20$ " and "current smoker as positive predictors for COPD and showed a sensitivity and a specificity of 45\% [95\% CI 30-60\%], and of $89 \%$ [95\% CI 81-94\%], respectively. The positive and negative predictive values were $61 \%$ [95\% CI 42-76\%], and 81\% [95\% CI 73-87\%], respectively. Although variable "current smoker" did not show a significant association with COPD, it was used as a confounder since it caused the odds ratios of the top variables (age, pack years) to vary by more than $10 \%$. The area under the receiver/response operating characteristic (ROC) curve was 0.83 (Figure 4). Finally, the proportion of correctly classified observations (COPD or non-COPD) was $77 \%$.

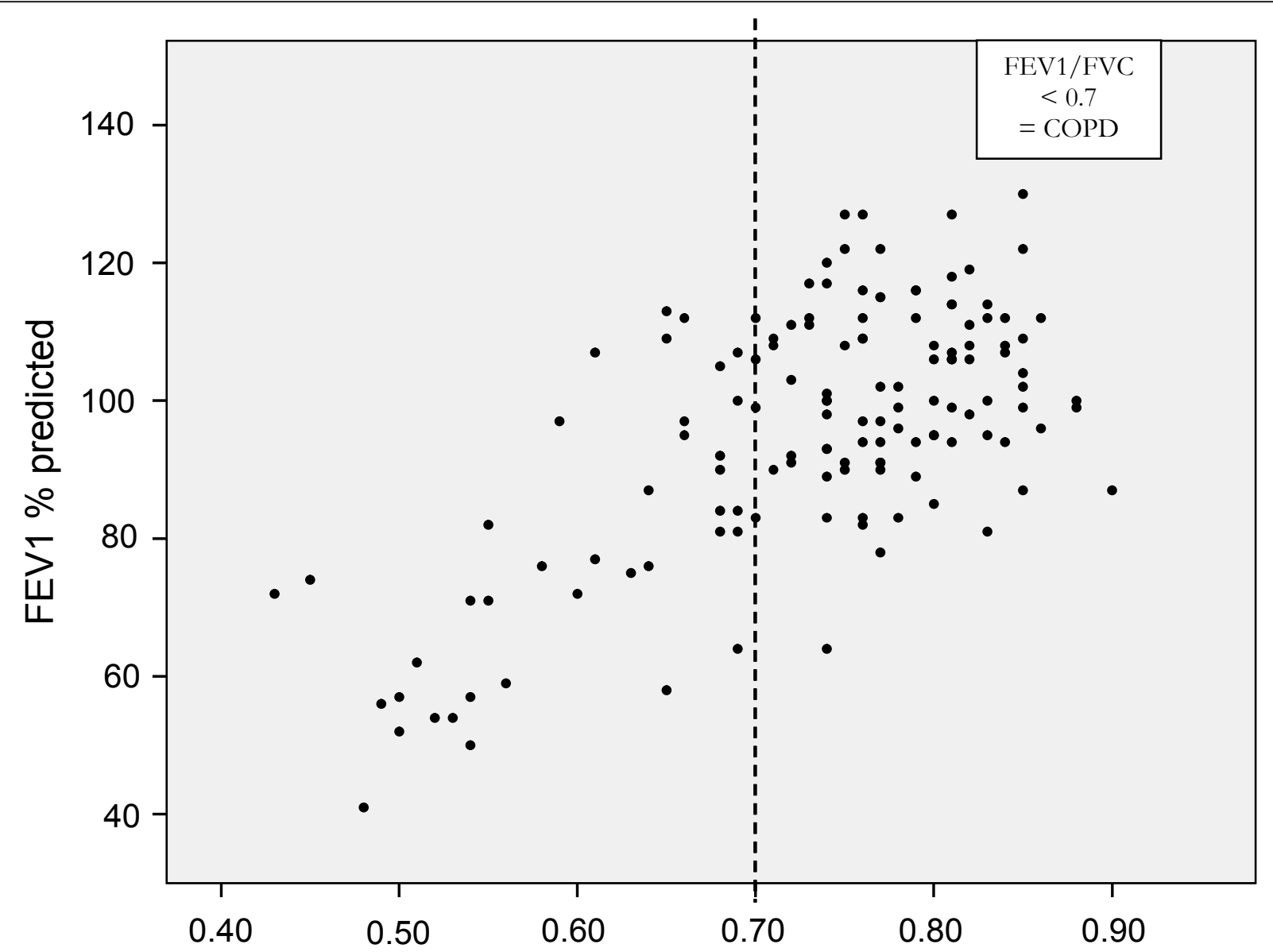

FEV1/FVC ratio

Figure 2 Results of spirometry in 138 patients seeking urgent primary care for respiratory infections. 


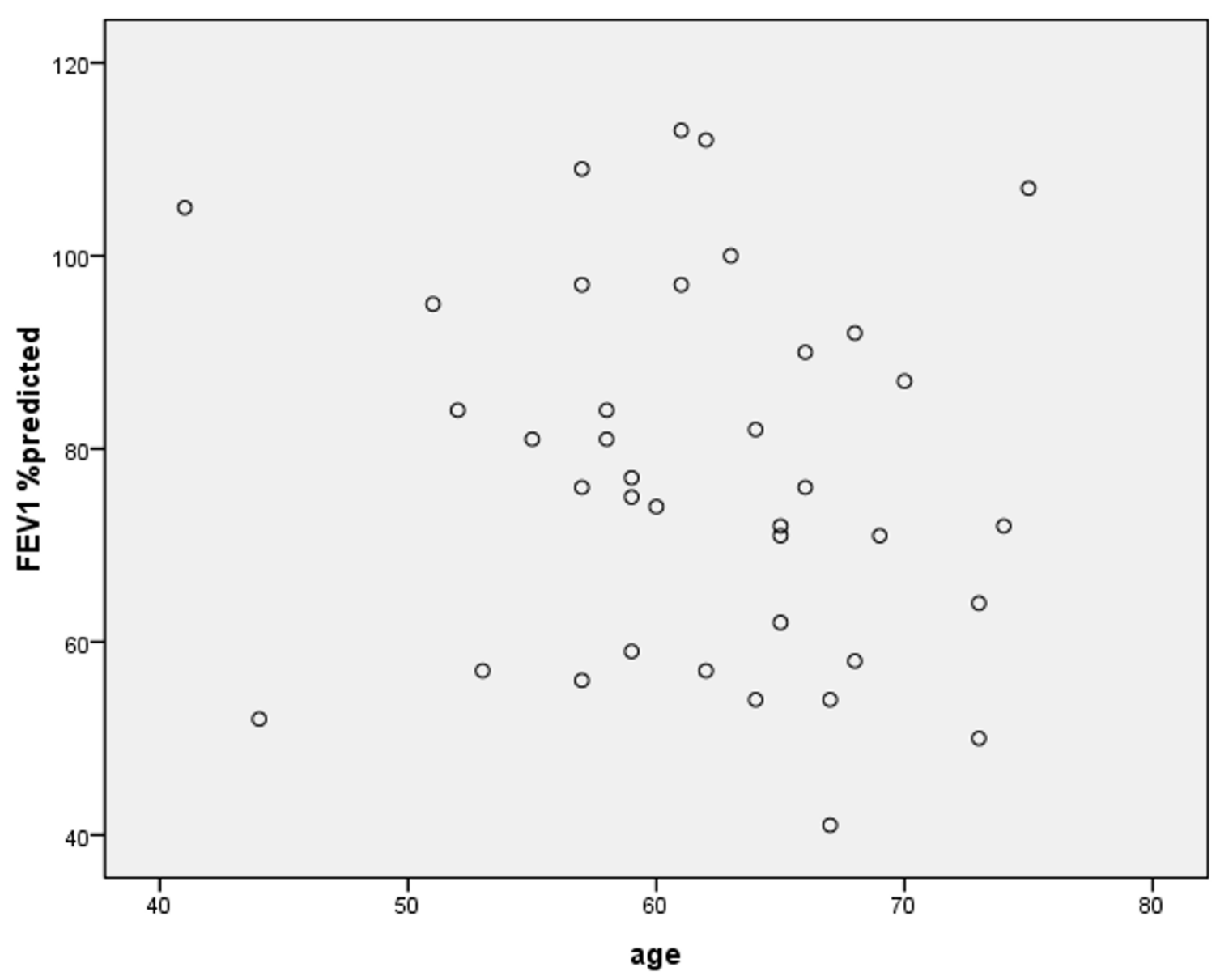

Figure 3 Correlation of FEV1 (\% predicted) and age (years) for all participants with COPD.

Nineteen percent $(n=40)$ of patients who were invited to undergo spirometry failed to show for their appointments. The dropout rate was independent of sex, age and infection diagnosis. However, smoking status (current or ex-smoker) and intensity (pack years) of patients who dropped out were not recorded.

\section{Discussion}

There is an ongoing discussion about how to improve early detection of COPD. In this case finding study we found a high prevalence (27\%) of previously undiagnosed COPD. Statistical analysis showed that assessing three simple variables (age, smoking intensity and

Table 3 The odds ratio (OR) for having COPD

\begin{tabular}{|c|c|c|c|}
\hline & & & COPD \\
\hline \multirow[t]{2}{*}{ Age } & Years & $\geq 55$ & $10.9[3.8-30.1]$ \\
\hline & & $<55$ & 1.0 \\
\hline \multirow[t]{2}{*}{ Smoking intensity } & Pack years & $\geq 20$ & $3.2[1.2-8.5]$ \\
\hline & & $<20$ & 1.0 \\
\hline \multirow[t]{2}{*}{ Smoking status } & Current smoker & yes & $2.5[0.9-6.6]$ \\
\hline & & no & 1.0 \\
\hline \multirow[t]{2}{*}{ Diagnosis } & & Upper respiratory infection & $0.8[0.3-2.0]$ \\
\hline & & Lower respiratory infection & 1.0 \\
\hline \multirow[t]{2}{*}{ Sex } & & female & $0.9[0.3-2.1]$ \\
\hline & & male & 1.0 \\
\hline
\end{tabular}




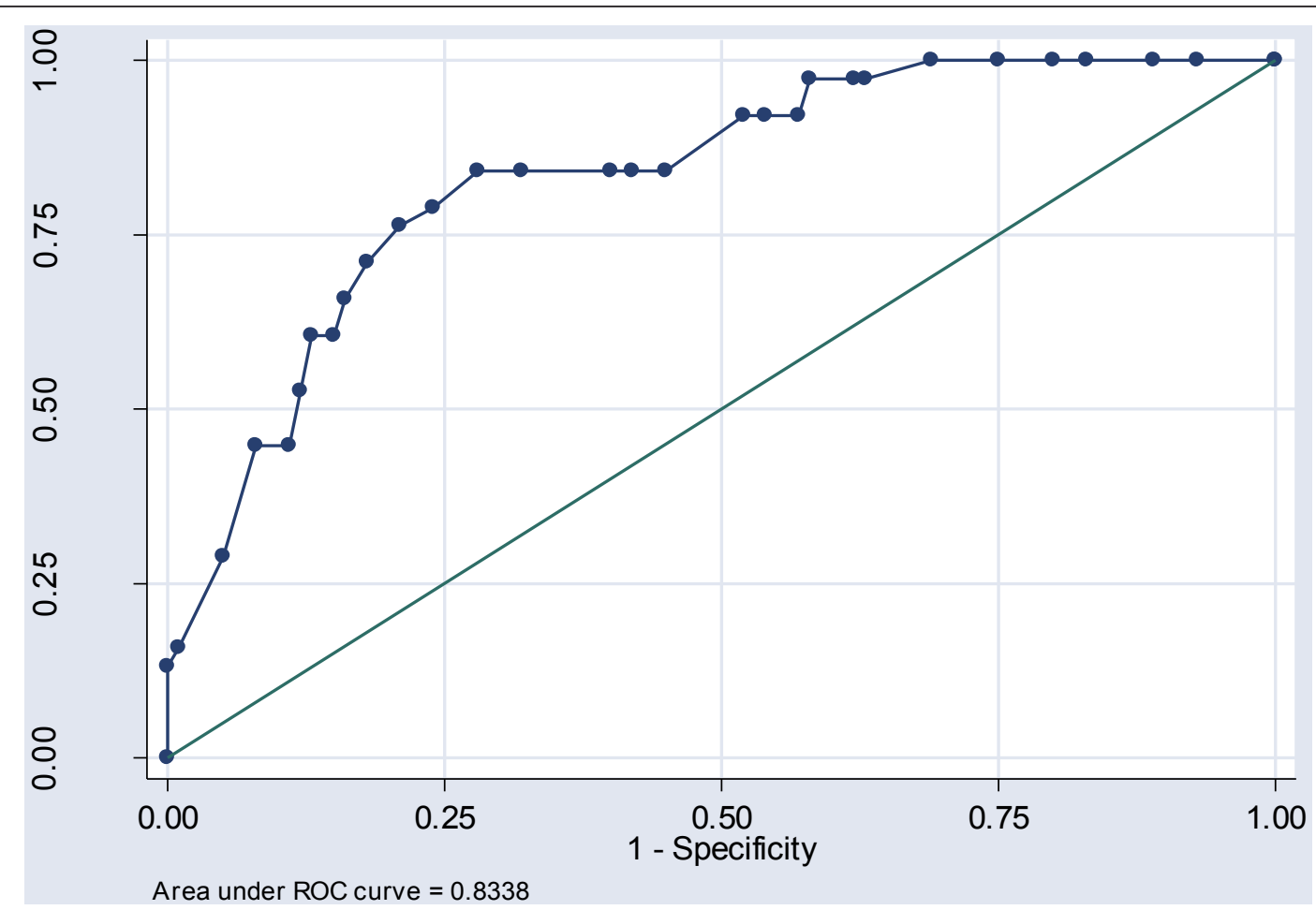

Figure 4 Receiver/response operating characteristic (ROC) curve adjusted for age, pack years, current smoking, sex and infection diagnosis.

smoking status) among patients with any kinds of acute respiratory infections attending urgent primary care could be a feasible and effective way to short-list those who need spirometry testing to confirm the presence of underlying COPD. Moreover, preliminary screening for airflow obstruction using a handheld spirometer prior to full spirometry testing may be an efficient way of finding new COPD cases [29].

In comparison with other case finding methods, such as questionnaires and random screenings of smokers this study utilized a targeted approach in a real-life context $[9,13,23,30]$. In addition, such an approach would be suitable in urgent care settings, where consultation time is usually limited. Questionnaires may be more appropriate in clinical settings other than urgent primary care where more time for consultation is available.

The distribution patterns of different stages of COPD matched previous prevalence estimates $[7,9,10]$ and indicated early COPD. The distribution of stage 1 was found to be independent of age ruling out the possibility of overdiagnosis among the elderly persons in this study population. Instead, $53 \%$ of undiagnosed COPD cases were in stage 2 (moderate) and $45 \%$ in stage 1 (mild) suggesting not only that underdiagnosis of COPD may be common but also that underdiagnosis of moderately advanced stages of COPD may be common. In effect, underdiagnosis has been shown in earlier epidemiological studies of COPD among primary care patients $[9,11,31]$. These studies have shown that underdiagnosis of COPD occured partly because of "doctor's delay", i.e., doctors who don't suspect underlying COPD [32,33] and partly because of "patient's delay", i.e, patients who self-report good health [34].

The major strength of the study is its connection and relevance to real-life contexts in primary health care. Our case finding approach suggests that both patients and doctors play an active role in the early detection of COPD which, in turn, may lead to new diagnoses and patients with increased motivation to quit smoking [35].

To our knowledge, no case finding study has been performed in a study group similar to ours. A high prevalence of COPD among patients with LRTI and positive smoking history has been shown earlier [31]. Interestingly, a fourth of patients with URTI in our study had a previously undiagnosed COPD and prevalence among all patients was independent of the infection site, i.e, upper or lower respiratory tract. However, due to the small sample size, conclusions should be drawn with caution. More studies on the role of the infection site in the detection of COPD are needed. Prevalence of COPD in our study population was consistent with that observed in earlier studies $[9,11,31]$. Prevalence of undiagnosed COPD among smokers is largely known to be approximately $20-50 \%$ depending on smoker's age and smoking intensity [8]. 
Although the women with undiagnosed COPD in the group were younger than the men, we found no association between prevalence of COPD and sex. This finding was inconsistent with earlier studies, though the small sample size may explain the discrepancy. Recent evidence has suggested that women are at higher risk of developing COPD than men accompanied by an earlier onset and a more severe clinical manifestation of the disease [36,37]. Prevalence of COPD among women is likely to increase due to changes in smoking habits of women [38].

The positive $(61 \%)$ and negative $(81 \%)$ predictive values of our model, which utilized three variables (age, smoking status and intensity) to detect COPD in patients with an acute respiratory tract infection were relatively high. A possible explanation for this outcome may be that multiple regression analysis was influenced by the presence of random factors typical for small-sample studies.

Having said that, the small sample size was the main limitation of this study. In addition, the exclusion of patients aged 75 years or over and patients with severe cardiac disease and severe psychiatric diagnoses, among whom prevalence of COPD has been shown to be high [39], is another notable limitation of this study. The reason for excluding those patient groups was the particular focus of this study on patients who do not normally attend primary care. As a consequence, we may have observed a lower prevalence of COPD than that reported in studies with broader inclusion criteria [14,40]. Also, although we were aware that the optimum time for performing spirometry on patients with COPD was six to seven weeks after an exacerbation [41], we chose to perform the test on our study population four to five weeks after infection onset since we had no prior knowledge of who had underlying COPD.

\section{Conclusion}

COPD is a potentially life-threatening disease whose progress can be slowed relatively easily and inexpensively by smoking cessation. We conclude that patients aged 40 or over with a positive smoking history (more than 20 pack years) who develop any type of respiratory infection may also have underlying COPD. Thus, it is crucial for physicians to identify this high-risk group and offer them spirometry testing for early detection of COPD, which may motivate those patients to quit smoking.

\section{Acknowledgements and funding}

Astra Zeneca Inc. provided spirometry devices. Farhad Alinaghizadeh, Center for Family and Community Medicine (CeFAM), Karolinska Institutet is gratefully acknowledged for statistical advice. A special thank also to Scientific Editor Stella Papadopoulou at the Center for Family and Community Medicine for valuable assistance with the text.

\section{Author details}

'Center for Family and Community Medicine (CeFAM), Department of Neurobiology, Care Sciences and Society, Karolinska Institutet, Alfred Nobels Allé 12, S-14183 Huddinge, Sweden. 'Bollmora Primary Health Care Center, Bollmoravägen 14, S-13540 Tyresö, Sweden. ${ }^{3}$ Department of Public Health and Caring Sciences, Family Medicine and Clinical Epidemiology, Uppsala University, BMC, Box 564, S-75122 Uppsala, Sweden.

\section{Authors' contributions}

HS participated in the design of the study, data collection and organization, performing spirometry testing, statistical analysis and manuscript drafting and critical revising. BS advised on and participated in statistical analyses, manuscript drafting and critical revising. AN participated in manuscript drafting and critical revising. $\mathrm{JH}$ participated in the design of the study and in manuscript drafting and critical revising. All authors read and approved the final version of the manuscript.

\section{Competing interests}

The authors declare that they have no competing interests and are solely responsible for the content of the paper.

Received: 23 August 2011 Accepted: 3 November 2011

Published: 3 November 2011

\section{References}

1. Lopez AD, Shibuya K, Rao C, Mathers CD, Hansell AL, Held LS, Schmid V, Buist S: Chronic obstructive pulmonary disease: current burden and future projections. Eur Respir J 2006, 27(2):397-412.

2. Halbert RJ, Isonaka S, George D, lqbal A: Interpreting COPD prevalence estimates: what is the true burden of disease? Chest 2003, 123(5):1684-1692.

3. Hansen JG, Pedersen L, Overvad K, Omland O, Jensen HK, Sorensen HT: The Prevalence of chronic obstructive pulmonary disease among Danes aged 45-84 years: population-based study. COPD 2008, 5(6):347-352.

4. Lokke A, Lange $P$, Scharling H, Fabricius P, Vestbo J: Developing COPD: a 25 year follow up study of the general population. Thorax 2006, 61(11):935-939.

5. Jansson SA, Andersson F, Borg S, Ericsson A, Jonsson E, Lundback B: Costs of COPD in Sweden according to disease severity. Chest 2002, 122(6):1994-2002.

6. Anthonisen NR, Connett JE, Kiley JP, Altose MD, Bailey WC, Buist AS, Conway WA Jr, Enright PL, Kanner RE, O'Hara P: Effects of smoking intervention and the use of an inhaled anticholinergic bronchodilator on the rate of decline of FEV1. The Lung Health Study. JAMA 1994, 272(19):1497-1505.

7. Hasselgren M, Arne M, Lindahl A, Janson S, Lundback B: Estimated prevalences of respiratory symptoms, asthma and chronic obstructive pulmonary disease related to detection rate in primary health care. Scand J Prim Health Care 2001, 19(1):54-57.

8. Lundback $B$, Lindberg $A$, Lindstrom $M$, Ronmark $E$, Jonsson AC, Jonsson $E$, Larsson LG, Andersson S, Sandstrom T, Larsson K: Not 15 but $50 \%$ of smokers develop COPD?-Report from the Obstructive Lung Disease in Northern Sweden Studies. Respir Med 2003, 97(2):115-122.

9. Stratelis G, Jakobsson P, Molstad S, Zetterstrom O: Early detection of COPD in primary care: screening by invitation of smokers aged 40 to 55 years. Br J Gen Pract 2004, 54(500):201-206.

10. Lindberg A, Bjerg A, Ronmark E, Larsson LG, Lundback B: Prevalence and underdiagnosis of COPD by disease severity and the attributable fraction of smoking Report from the Obstructive Lung Disease in Northern Sweden Studies. Respir Med 2006, 100(2):264-272.

11. Hill K, Goldstein RS, Guyatt GH, Blouin M, Tan WC, Davis LL, HeelsAnsdell DM, Erak M, Bragaglia PJ, Tamari IE: Prevalence and underdiagnosis of chronic obstructive pulmonary disease among patients at risk in primary care. CMAJ 2010, 182(7):673-678.

12. Walters JA, Hansen EC, Johns DP, Blizzard EL, Walters EH, Wood-Baker R: A mixed methods study to compare models of spirometry delivery in primary care for patients at risk of COPD. Thorax 2008, 63(5):408-414.

13. Price DB, Tinkelman DG, Halbert RJ, Nordyke RJ, Isonaka S, Nonikov D, Juniper EF, Freeman D, Hausen T, Levy ML: Symptom-based questionnaire for identifying COPD in smokers. Respiration 2006, 73(3):285-295. 
14. Vandevoorde J, Verbanck S, Gijssels L, Schuermans D, Devroey D, De Backer J, Kartounian J, Vincken W: Early detection of COPD: a case finding study in general practice. Respir Med 2007, 101(3):525-530.

15. Tinkelman DG, Price D, Nordyke RJ, Halbert RJ: COPD screening efforts in primary care: what is the yield? Prim Care Respir J 2007, 16(1):41-48.

16. Kaminsky DA, Marcy TW, Bachand M, Irvin CG: Knowledge and use of office spirometry for the detection of chronic obstructive pulmonary disease by primary care physicians. Respir Care 2005, 50(12):1639-1648.

17. Pinnock $H$, Thomas M, Tsiligianni I, Lisspers K, Ostrem A, Stallberg B, Yusuf O, Ryan D, Buffels J, Cals JW: The International Primary Care Respiratory Group (IPCRG) Research Needs Statement 2010. Prim Care Respir J 19(Suppl 1):S1-20.

18. Seemungal T, Harper-Owen R, Bhowmik A, Moric I, Sanderson G, Message S, Maccallum P, Meade TW, Jeffries DJ, Johnston SL: Respiratory viruses, symptoms, and inflammatory markers in acute exacerbations and stable chronic obstructive pulmonary disease. Am J Respir Crit Care Med 2001, 164(9):1618-1623.

19. Kherad O, Kaiser L, Bridevaux PO, Sarasin F, Thomas $Y$, Janssens JP, Rutschmann OT: Upper-respiratory viral infection, biomarkers, and COPD exacerbations. Chest 138(4):896-904.

20. Melbye $\mathrm{H}$ : Bronchial airflow limitation and chest findings in adults with respiratory infection. Scand J Prim Health Care 1995, 13(4):261-267.

21. Montnemery P, Svensson C, Adelroth E, Lofdahl CG, Andersson M, Greiff L, Persson CG: Prevalence of nasal symptoms and their relation to selfreported asthma and chronic bronchitis/emphysema. Eur Respir J 2001, 17(4):596-603.

22. Varkey JB, Varkey B: Viral infections in patients with chronic obstructive pulmonary disease. Curr Opin Pulm Med 2008, 14(2):89-94.

23. Van Schayck CP, Loozen JM, Wagena E, Akkermans RP, Wesseling GJ: Detecting patients at a high risk of developing chronic obstructive pulmonary disease in general practice: cross sectional case finding study. BMJ 2002, 324(7350):1370.

24. van de Lisdonk EH: Perceived and presented morbidity in general practice. A study with diaries in four general practices in The Netherlands. Scand J Prim Health Care 1989, 7(2):73-78.

25. Melbye $\mathrm{H}$, Kongerud J, Vorland L: Reversible airflow limitation in adults with respiratory infection. Eur Respir J 1994, 7(7):1239-1245.

26. Quanjer PH, Tammeling GJ, Cotes JE, Pedersen OF, Peslin R, Yernault JC: Lung volumes and forced ventilatory flows. Report Working Party Standardization of Lung Function Tests, European Community for Steel and Coal. Official Statement of the European Respiratory Society. Eur Respir J Suppl 1993, 16:5-40.

27. Corporation S: STATA statistical software. Stata Press; 8.02003

28. Zweig MH, Campbell G: Receiver-operating characteristic (ROC) plots: a fundamental evaluation tool in clinical medicine. Clin Chem 1993, 39(4):561-577.

29. Robalo Cordeiro C, Singh S, Herth FJ, Ley S, Chavannes NH, Clini E, Cottin V: Selected clinical highlights from the 2010 ERS Congress in Barcelona. Eur Respir J 2011, 38(1):209-217.

30. Kotz D, Nelemans P, van Schayck CP, Wesseling GJ: External validation of a COPD diagnostic questionnaire. Eur Respir J 2008, 31(2):298-303.

31. Yawn B, Mannino D, Littlejohn T, Ruoff G, Emmett A, Raphiou I, Crater G: Prevalence of COPD among symptomatic patients in a primary care setting. Curr Med Res Opin 2009, 25(11):2671-2677.

32. Albers M, Schermer T, Molema J, Kloek C, Akkermans R, Heijdra Y, van Weel C: Do family physicians' records fit guideline diagnosed COPD? Fam Pract 2009, 26(2):81-87.

33. Kesten S, Chapman KR: Physician perceptions and management of COPD. Chest 1993, 104(1):254-258

34. Hvidsten SC, Storesund L, Wentzel-Larsen T, Gulsvik A, Lehmann S: Prevalence and predictors of undiagnosed chronic obstructive pulmonary disease in a Norwegian adult general population. Clin Respir $J$ 2010, 4(1):13-21.

35. van Weel C: Underdiagnosis of asthma and COPD: is the general practitioner to blame? Monaldi Arch Chest Dis 2002, 57(1):65-68.

36. de Torres JP, Casanova C, Hernandez C, Abreu J, Aguirre-Jaime A, Celli BR: Gender and COPD in patients attending a pulmonary clinic. Chest 2005, 128(4):2012-2016.

37. van Haren-Willems J, Heijdra Y: Increasing evidence for gender differences in chronic obstructive pulmonary disease. Womens Health (Lond Engl) 2010, 6(4):595-600
38. Samet JM, (Ed.): Gender, women, and the tobacco epidemic Geneva: World Health Organization; 2010.

39. Cazzola M, Bettoncelli G, Sessa E, Cricelli C, Biscione G: Prevalence of comorbidities in patients with chronic obstructive pulmonary disease. Respiration 2010, 80(2):112-119.

40. Ulrik CS, Lokke A, Dahl R, Dollerup J, Hansen G, Cording PH, Andersen KK: Early detection of COPD in general practice. Int J Chron Obstruct Pulmon Dis 2011, 6:123-127.

41. Seemungal TA, Donaldson GC, Bhowmik A, Jeffries DJ, Wedzicha JA: Time course and recovery of exacerbations in patients with chronic obstructive pulmonary disease. Am J Respir Crit Care Med 2000, 161(5):1608-1613.

\section{Pre-publication history}

The pre-publication history for this paper can be accessed here: http://www.biomedcentral.com/1471-2296/12/122/prepub

\section{doi:10.1186/1471-2296-12-122}

Cite this article as: Sandelowsky et al:: The prevalence of undiagnosed chronic obstructive pulmonary disease in a primary care population with respiratory tract infections - a case finding study. BMC Family

Practice 2011 12:122.

\section{Submit your next manuscript to BioMed Central and take full advantage of:}

- Convenient online submission

- Thorough peer review

- No space constraints or color figure charges

- Immediate publication on acceptance

- Inclusion in PubMed, CAS, Scopus and Google Scholar

- Research which is freely available for redistribution

Submit your manuscript at www.biomedcentral.com/submit
C) Biomed Central 